\title{
Hydrogenation of Some Vegetable Oils by Scrap Automobile Catalyst
}

\author{
Fatih Sonmez, Hakan Ercan, Hayriye Genc, Mustafa Arslan, \\ Mustafa Zengin, and Mustafa Kucukislamoglu \\ Department of Chemistry, Faculty of Art and Sciences, Sakarya University, 54140 Sakarya, Turkey \\ Correspondence should be addressed to Mustafa Kucukislamoglu; mustafak@sakarya.edu.tr
}

Received 19 June 2012; Revised 4 September 2012; Accepted 5 September 2012

Academic Editor: Cristina Femoni

Copyright (c) 2013 Fatih Sonmez et al. This is an open access article distributed under the Creative Commons Attribution License, which permits unrestricted use, distribution, and reproduction in any medium, provided the original work is properly cited.

\begin{abstract}
Some vegetable oils were hydrogenated with scrap automobile catalyst (SAC) as a catalyst. The optimum reaction conditions (solvent, reaction time, and catalyst amount) were determined. Our results showed that the linoleic acid was reduced to elaidic acid in the sunflower oil. This procedure not only gives high yields but also allows recycling of automobile wastes as a catalyst in organic reactions and is representative of green chemistry.
\end{abstract}

\section{Introduction}

Hydrogenation of fats and oils is a very important operation in the industrial process of producing vegetable tallow, vegetable fats, margarines, and starting components for the cosmetic and chemical industry such as emulsifiers, soaps, creams, pastes, and similar substances [1]. There are two main reasons why hydrogenation is important to the industry. The first is increasing the stability of the oil. Highly unsaturated oil is susceptible to autoxidation, thermal decomposition, and other reactions that affect the flavor. Consequently, it is desired to partially hydrogenate the oil to improve shelf life. The second reason to partially hydrogenate vegetable oil is to improve its utility. For most products, such as shortenings, margarines, or confectionery fats, the desired softening and melting characteristics correspond to oils that are partially hydrogenated. The choice of catalyst to use for hydrogenation greatly affects the properties of the final product [2].

Several catalysts for hydrogenation of oils are known in the literature, such as Rh/TPPTS complexes [3], $\mathrm{Cu} / \mathrm{SiO}_{2}$ [4], $\mathrm{Ni} / \mathrm{SiO}_{2}$ [5] and $\mathrm{Pd} / \mathrm{SiO}_{2}$ [6-8] catalysts, $\mathrm{Ni} / \mathrm{Ru}$ mixture [9], and $\mathrm{Ni} / \mathrm{Al}_{2} \mathrm{O}_{3}$ catalyst [10].

In continuation of our studies on the development of novel heterogeneous synthetic methodologies [11-14], we have achieved a novel procedure for the hydrogenation of sunflower oils catalyzed by scrap automobile catalyst (SAC) which was used for the hydrogenation of carbon-carbon double bonds in our previous study [15].

The lifetime of catalytic converters is limited and thus their recycling is crucial. Catalytic converters consist of a ceramic substrate coated with aluminum oxide $\left(\mathrm{Al}_{2} \mathrm{O}_{3}\right)$ and other rare earth oxides, such as $\mathrm{CeO}_{2}, \mathrm{ZrO}_{2}, \mathrm{Pt}, \mathrm{Pd}$, and $\mathrm{Rh}$ which are responsible for the catalytic function [16]. A used automobile catalytic converter was taken from a Fiat Siena after running for $140,000 \mathrm{~km}$. After purification of the SAC, it was activated in an oven maintained at $120^{\circ} \mathrm{C}$ for $12 \mathrm{~h}$ and found to contain $0.465 \% \mathrm{Pd}$ and $0.040 \% \mathrm{Rh}$ by XRF analysis.

\section{Experimental Procedures}

2.1. General. ${ }^{1} \mathrm{H}$ and ${ }^{13} \mathrm{C}$ NMR spectra were measured on spectrometer at VARIAN Infinity Plus 300 and at $75 \mathrm{~Hz}$, respectively. ${ }^{1} \mathrm{H}$ and ${ }^{13} \mathrm{C}$ chemical shifts are referenced to the internal deuterated solvent. Solvents were dried following standard methods. All chemicals were purchased from Merck, Alfa Easer, Sigma-Aldrich, and Fluka and the oils were purchased from local supermarket.

2.2. Purification of the Catalyst. A piece of scrap catalyst $(50 \mathrm{~g})$ cut by hacksaw was taken from the automobile catalytic converter and washed with chromic acid and distilled water 
TABLE 1: Catalytic hydrogenation of some vegetable oils using SAC.

\begin{tabular}{|c|c|c|c|c|c|}
\hline Oil type & Time (h) & Amount of oil (g) & Amount of catalyst (g) & Solvent & Iodine value \\
\hline \multirow{17}{*}{ Sunflower oil } & - & 4 & - & - & 117.00 \\
\hline & 48 & 4 & 1 & THF & 112.55 \\
\hline & 48 & 4 & 2 & THF & 88.88 \\
\hline & 48 & 4 & 3 & THF & 42.70 \\
\hline & 48 & 4 & 4 & THF & 23.68 \\
\hline & 6 & 4 & 4 & THF & 54.01 \\
\hline & 12 & 4 & 4 & THF & 53.71 \\
\hline & 18 & 4 & 4 & THF & 45.47 \\
\hline & 24 & 4 & 4 & THF & 39.70 \\
\hline & 30 & 4 & 4 & THF & 36.63 \\
\hline & 36 & 4 & 4 & THF & 34.44 \\
\hline & 42 & 4 & 4 & THF & 30.69 \\
\hline & 72 & 4 & 4 & THF & 22.77 \\
\hline & 48 & 4 & 4 & Diethyl ether & 32.71 \\
\hline & 48 & 4 & 4 & Hexane & 44.18 \\
\hline & 48 & 4 & 4 & Acetone & 35.73 \\
\hline & 48 & 4 & 4 & Isopropanol & 34.48 \\
\hline \multirow{2}{*}{ Hazelnut oil } & - & 4 & - & - & 89.96 \\
\hline & 48 & 4 & 4 & THF & 30.38 \\
\hline \multirow{2}{*}{ Tea seed oil } & - & 4 & - & - & 57.52 \\
\hline & 48 & 4 & 4 & THF & 20.96 \\
\hline
\end{tabular}

to remove dust and carbonaceous particles. The scrap catalyst was dried in an oven maintained at $120^{\circ} \mathrm{C}$ for $12 \mathrm{~h}$, crushed in agate mortar and sieved $(<100 \mu \mathrm{m}$ in diameter $)$, and analyzed by XRF.

2.3. Optimization of Reaction Conditions. To optimize the hydrogenation reaction, we examined the reaction conditions in different solvents, such as THF, diethyl ether, hexane, isopropanol, and acetone, for the different reaction times $(6 \mathrm{~h}$, $12 \mathrm{~h}, 18 \mathrm{~h}, 24 \mathrm{~h}, 30 \mathrm{~h}, 36 \mathrm{~h}, 42 \mathrm{~h}, 48 \mathrm{~h}$, and $72 \mathrm{~h}$ ) and different amount of catalyst ( $1 \mathrm{~g}, 2 \mathrm{~g}, 3 \mathrm{~g}$, and $4 \mathrm{~g}$ ). We determined optimization by low iodine value. Thus, the best results were obtained in THF for $48 \mathrm{~h}$ with $4 \mathrm{~g}$ catalyst (Table 1 ).

2.4. Hydrogenation Procedures. A solution of the sunflower oil $(4.0 \mathrm{~g})$ in anhydrous THF $(25 \mathrm{~mL})$ was transferred into a two-neck round bottom flask containing the purified catalyst ( $4 \mathrm{~g}$ ). Reactions were carried out by stirring under atmospheric pressure of $\mathrm{H}_{2}$ at room temperature for $48 \mathrm{~h}$. The reaction mixture was filtered and the filtrate was evaporated under vacuum.

2.5. Iodine Value. Iodine values of the partially hydrogenated oils were determined by the known procedures [17].

\section{Results and Discussion}

To optimize study of this hydrogenation reaction, the solvent effect of these liquid phase hydrogenation reactions depended on the solubility and chemisorption of $\mathrm{H}_{2}$ and on the catalyst suspended in the solvent. The solubility and chemisorption of $\mathrm{H}_{2}$ in a nonpolar solvent are greater than in polar solvents [18]. Also, rising reaction times and amount of catalyst increased the amount of hydrogenated oils. After 48 hours, rising the hydrogenation was quite sluggish (Table 1). So, the optimum reaction time was considered 48 hours.

The ${ }^{1} \mathrm{H}$ and ${ }^{13} \mathrm{C}$ NMR spectra of oils have been reported in the literature [19-21]. The ${ }^{1} \mathrm{H}$ NMR spectra of sunflower oil, which contains linoleic acid (58\%), oleic acid (31\%), stearic acid, and palmitic acid (11\%), show signals between 5.30 and $5.40 \mathrm{ppm}$ relating to olefinic protons of all acyl chains, at $2.75 \mathrm{ppm}$ for bisallylic protons and at $2.04 \mathrm{ppm}$ for allylic protons of linoleyl chains (Figure 1(a)). On the other hand, the signals of bisallylic protons and allylic protons of linoleyl chains cannot be seen at the ${ }^{1} \mathrm{H}$ NMR spectra of hydrogenated sunflower oil (Figure 1(b)) and it shows that the intensity of signals of the olefinic protons decreased. Although the signals of C9-10 and C1213 carbons of linoleic acid can be seen between 128.1 and $130.3 \mathrm{ppm}$ at the ${ }^{13} \mathrm{C}$ NMR spectra of sunflower oil (Figure 2(a)), they cannot be seen at ${ }^{13} \mathrm{C}$ NMR spectra of hydrogenated sunflower oil (Figure 2(b)). Additionally, the ${ }^{13} \mathrm{C}$ NMR spectra of hydrogenated sunflower oil showed a chemical shift for the trans-allylic carbons at $32.8 \mathrm{ppm}$ but no chemical shift at $27.3 \mathrm{ppm}$ [22], confirming that no cisisomers were present in this product. Based on these results, the linoleic acid was hydrogenated to elaidic acid in the sunflower oil. These results are consistent with declining iodine value and confirm the hydrogenation of sunflower oil. 


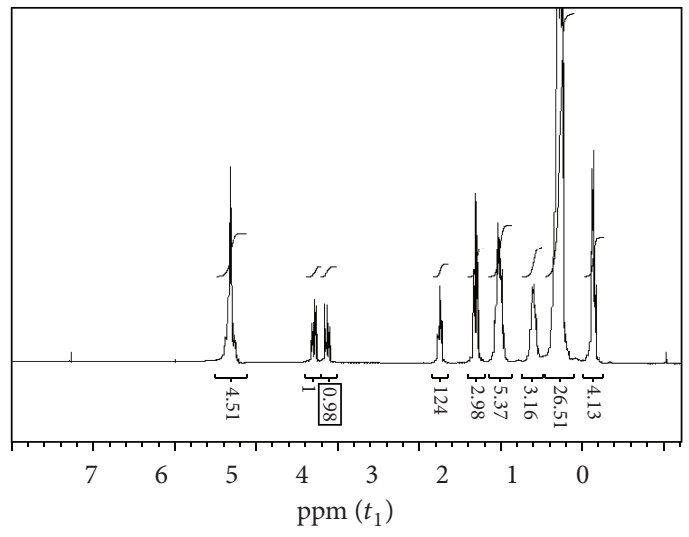

(a)

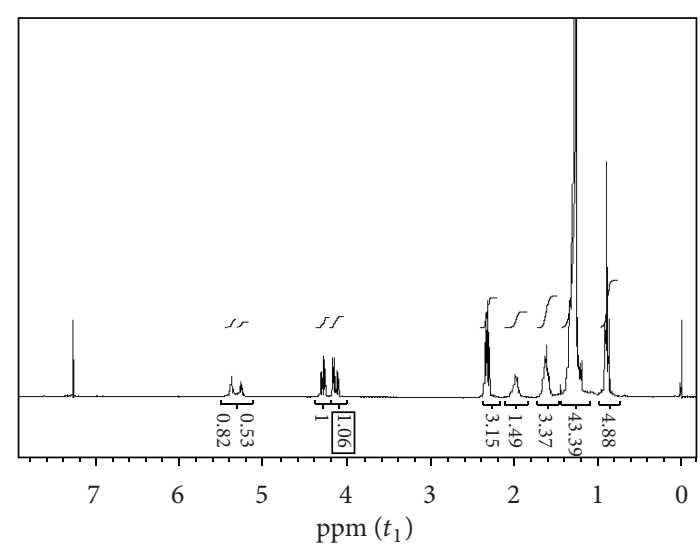

(b)

FIGURE 1: Comparison of the $300 \mathrm{MHz}^{1} \mathrm{H}-\mathrm{NMR}$ spectra of sunflower oil (a) and hydrogenated sunflower oil (b) in $\mathrm{CDCl}_{3}$ solutions.

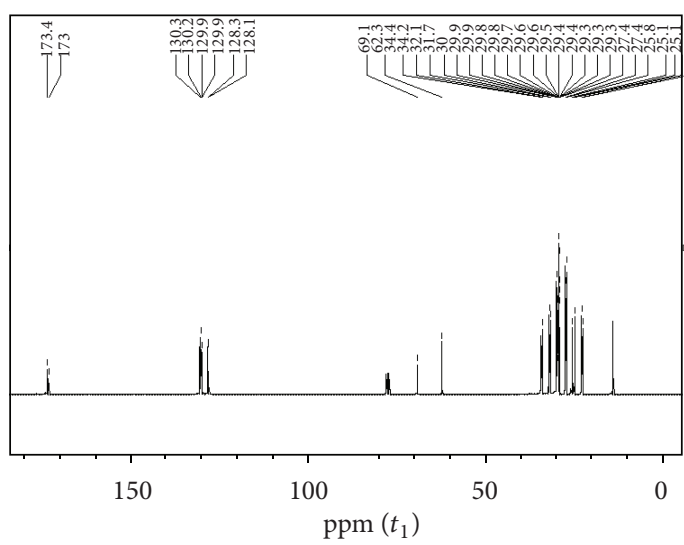

(a)

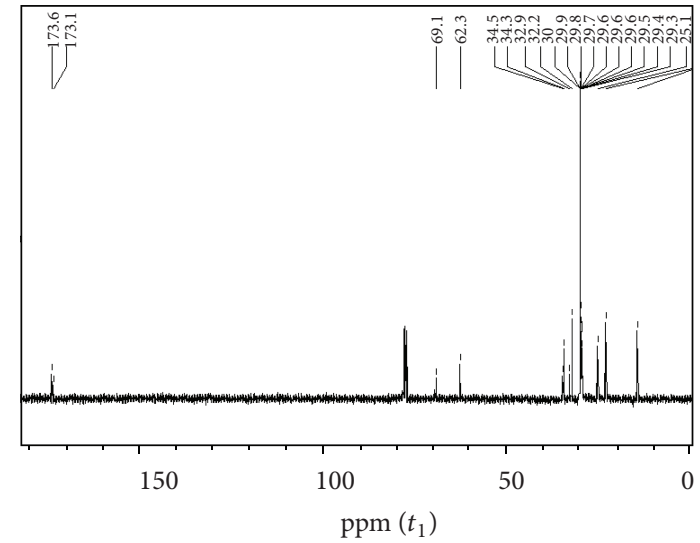

(b)

FIGURE 2: Comparison of the $75 \mathrm{MHz}^{13} \mathrm{C}-\mathrm{NMR}$ spectra of sunflower oil (a) and hydrogenated sunflower oil (b) in $\mathrm{CDCl}_{3}$ solutions.

After the sunflower oil was hydrogenated with SAC successfully, the hazelnut oil and tea seed oil were hydrogenated with the same procedures and similar results were observed. The iodine values were given in Table 1.

\section{Conclusions}

In conclusion, we have developed a process-friendly, efficient, cheap, and green procedure for the hydrogenation of sunflower oil catalyzed by scrap automobile catalyst (SAC) and this hydrogenation procedure was performed on the hazelnut oil and tea seed oil successfully. This method can be used in the fats, oils, and chemical industry.

\section{Acknowledgments}

The authors thank Mr. Malik Kurtuldu from Ozen Ekzost, Sakarya for supplying spent automotive catalyst and Senol Ozturk (Gizem Frit Sakarya) for XRF analysis.

\section{References}

[1] D. Jovanovic, R. Radovic, L. Mares, M. Stankovic, and B. Markovic, "Nickel hydrogenation catalyst for tallow hydrogenation and for the selective hydrogenation of sunflower seed oil and soybean oil," Catalysis Today, vol. 43, no. 1-2, pp. 21-28, 1998.

[2] M. W. Balakos and E. E. Hernandez, "Catalyst characteristics and performance in edible oil hydrogenation," Catalysis Today, vol. 35, no. 4, pp. 415-425, 1997.

[3] A. Bouriazos, S. Sotiriou, C. Vangelis, and G. Papadogianakis, "Catalytic conversions in green aqueous media: part 4. Selective hydrogenation of polyunsaturated methyl esters of vegetable oils for upgrading biodiesel," Journal of Organometallic Chemistry, vol. 695, no. 3, pp. 327-337, 2010.

[4] N. Ravasio, F. Zaccheria, M. Gargano et al., "Environmental friendly lubricants through selective hydrogenation of rapeseed oil over supported copper catalysts," Applied Catalysis A, vol. 233, no. 1-2, pp. 1-6, 2002.

[5] M. A. Ermakova and D. Y. Ermakov, "High-loaded nickel-silica catalysts for hydrogenation, prepared by sol-gel: route: structure and catalytic behavior," Applied Catalysis A, vol. 245, pp. 277-288, 2003. 
[6] M. Plourde, K. Belkacemi, and J. Arul, "Hydrogenation of sunflower oil with novel Pd catalysts supported on structured silica," Industrial and Engineering Chemistry Research, vol. 43, no. 10, pp. 2382-2390, 2004.

[7] M. B. Fernández, G. M. Tonetto, G. H. Crapiste, M. L. Ferreira, and D. E. Damiani, "Hydrogenation of edible oil over Pd catalysts: a combined theoretical and experimental study," Journal of Molecular Catalysis A, vol. 237, no. 1-2, pp. 67-79, 2005.

[8] K. Belkacemi, A. Boulmerka, J. Arul, and S. Hamoudi, "Hydrogenation of vegetable oils with minimum trans and saturated fatty acid formation over a new generation of Pd-catalyst," Topics in Catalysis, vol. 37, no. 2-4, pp. 113-120, 2006.

[9] A. J. Wright, A. L. Mihele, and L. L. Diosady, "Cis selectivity of mixed catalyst systems in canola oil hydrogenation," Food Research International, vol. 36, no. 8, pp. 797-804, 2003.

[10] B. W. Hoffer, A. D. Langeveld, J. P. Janssens, R. L. C. Bonné, C. M. Lok, and J. A. Moulijn, "Stability of highly dispersed $\mathrm{Ni} / \mathrm{Al}_{2} \mathrm{O}_{3}$ catalysts: effects of pretreatment," Journal of Catalysis, vol. 192, no. 2, pp. 432-440, 2000.

[11] M. Kucukislamoglu, M. Nebioglu, M. Zengin, M. Arslan, and N. Yayli, "An environmentally benign synthesis of flavones from 1,3-diketones using silica gel supported An environmentally benign synthesis of flavones from 1,3-diketones using silica gel supported $\mathrm{NaHSO}_{4}$ catalyst ${ }_{4}$ catalyst," Journal of Chemical Research, vol. 2005, no. 9, pp. 556-557, 2005.

[12] S. Besoluk, M. Kucukislamoglu, M. Nebioglu, M. Zengin, and M. Arslan, "Solvent-free synthesis of dihydropyrimidinones catalyzed by alumina sulfuric acid at room temperature," Journal of the Iranian Chemical Society, vol. 5, no. 1, pp. 62-66, 2008.

[13] M. Arslan, C. Faydali, M. Zengin, M. Küçükislamoğlu, and H. Demirhan, "An efficient one pot synthesis of 1,4dihydropyridines using alumina sulfuric acid (ASA) catalyst," Turkish Journal of Chemistry, vol. 33, no. 6, pp. 769-774, 2009.

[14] S. Besoluk, M. Kucukislamoglu, M. Zengin, M. Arslan, and M. Nebioglu, "An efficient one-pot synthesis of dihydropyrimidinones catalyzed by zirconium hydrogen phosphate under solvent-free conditions," Turkish Journal of Chemistry, vol. 34, no. 3, pp. 411-416, 2010.

[15] M. Zengin, H. Genc, T. Demirci, M. Arslan, and M. Kucukislamoglu, "An efficient hydrogenation of various alkenes using scrap automobile catalyst," Tetrahedron Letters, vol. 52, no. 18, pp. 2333-2335, 2011.

[16] M. Saternus and A. Fornalczyk, "Removal of platinum group metals from the used auto catalytic converter," Metalurgija, vol. 48, no. 2, pp. 133-136, 2009.

[17] D. Firestone, Official Methods and Recommended Practices of the American Oil Chemists Society, AOCS Press, Champaign, Ill, USA, 4th edition, 1990.

[18] U. K. Singh and M. A. Vannice, "Kinetics of liquid-phase hydrogenation reactions over supported metal catalysts-a review," Applied Catalysis A, vol. 213, no. 1, pp. 1-24, 2001.

[19] E. Hatzakis, A. Agiomyrgianaki, S. Kostidis, and P. Dais, "High-resolution NMR spectroscopy: an alternative fast tool for qualitative and quantitative analysis of diacylglycerol (DAG) oil," Journal of the American Oil Chemists' Society, vol. 88, no. 11, pp. 1695-1708, 2011.

[20] M. D. Guillen and A. Ruiz, "High resolution ${ }^{1} \mathrm{H}$ nuclear magnetic resonance in the study of edible oils and fats," Trends in Food Science \& Technology, vol. 12, no. 9, pp. 328-338, 2001.
[21] F. J. Hidalgo and R. Zamora, "Edible oil analysis by highresolution nuclear magnetic resonance spectroscopy: recent advances and future perspectives," Trends in Food Science \& Technology, vol. 14, no. 12, pp. 499-506, 2003.

[22] R. E. McDonald, D. J. Armstrong, and G. P. Kreishman, "Identification of trans-diene isomers in hydrogenated soybean oil by gas chromatography, silver nitrate thin-layer chromatography, and ${ }^{13} \mathrm{C}$ NMR spectroscopy," Journal of Agricultural and Food Chemistry, vol. 37, no. 3, pp. 637-642, 1989. 

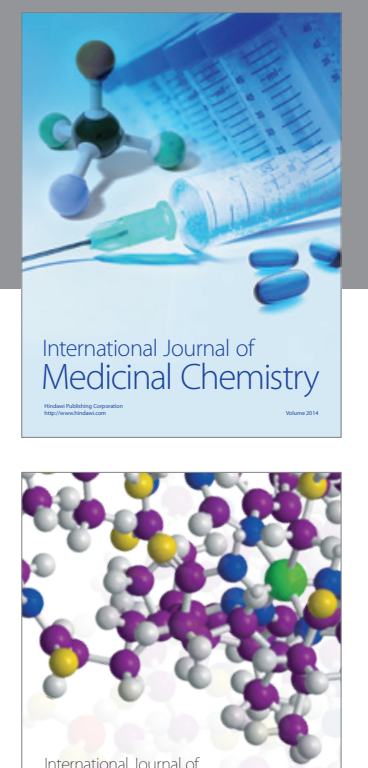

\section{Carbohydrate} Chemistry

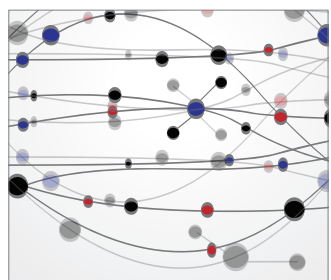

The Scientific World Journal
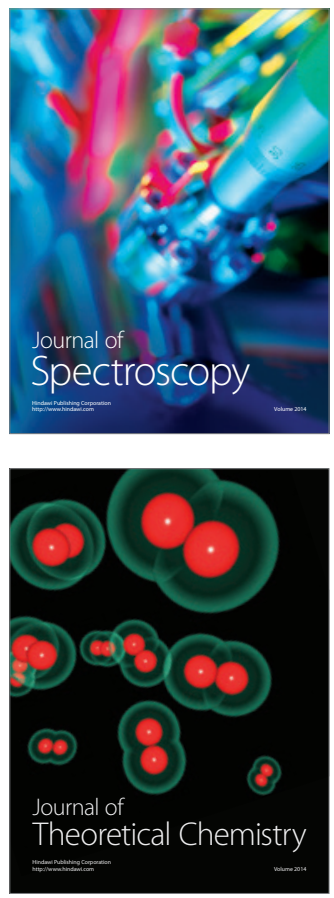
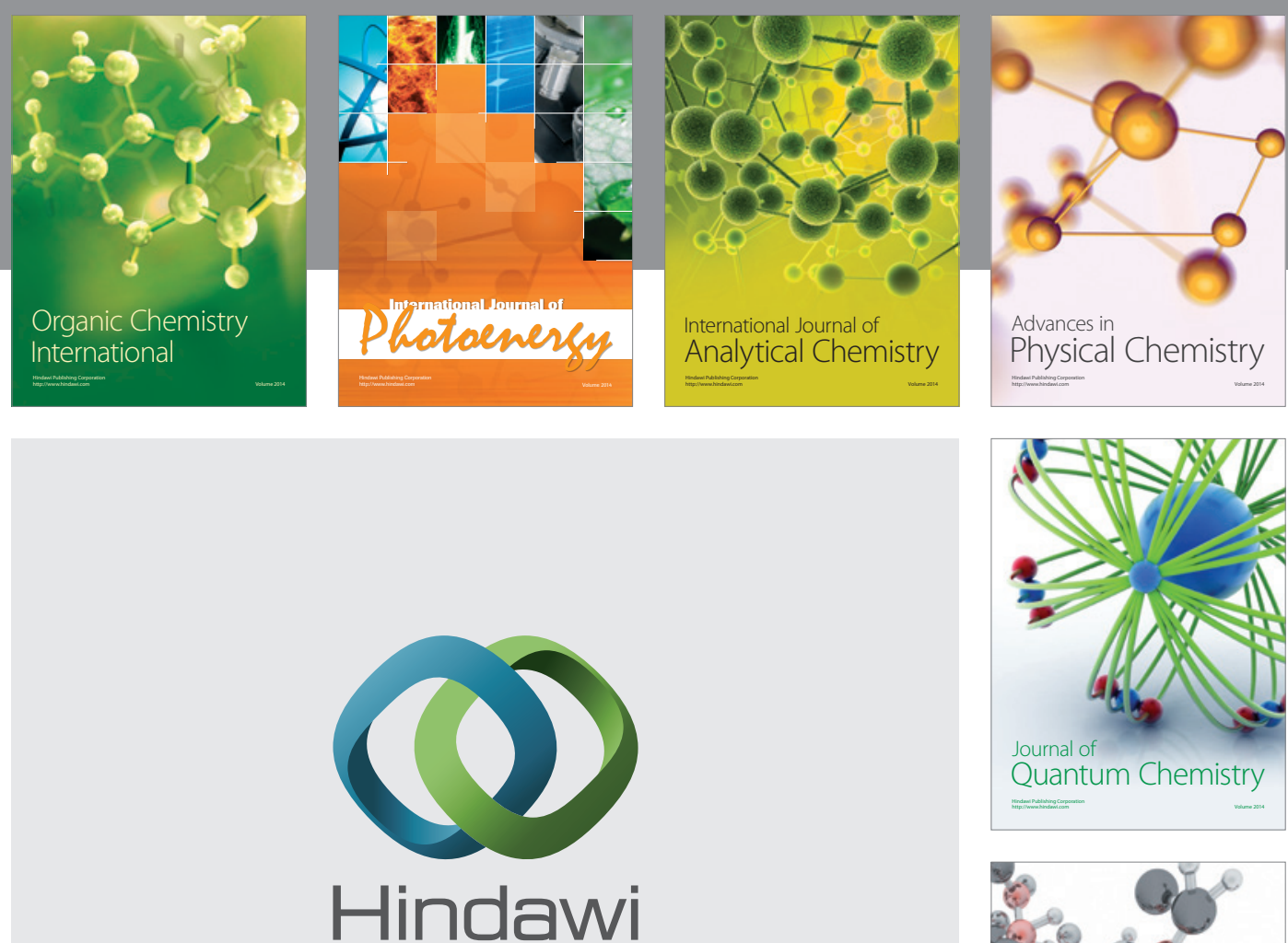

Submit your manuscripts at

http://www.hindawi.com

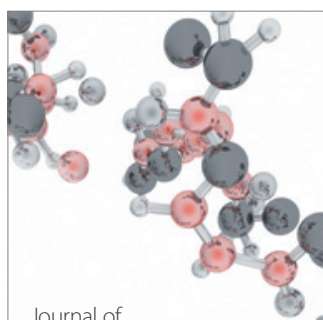

Analytical Methods

in Chemistry

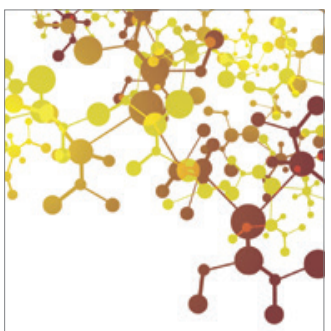

Journal of

Applied Chemistry

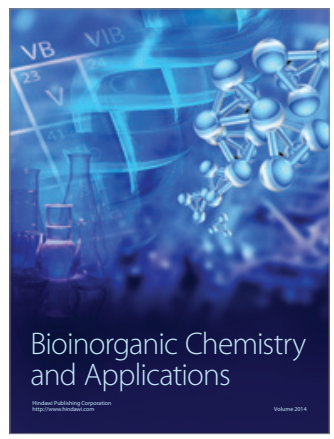

Inorganic Chemistry
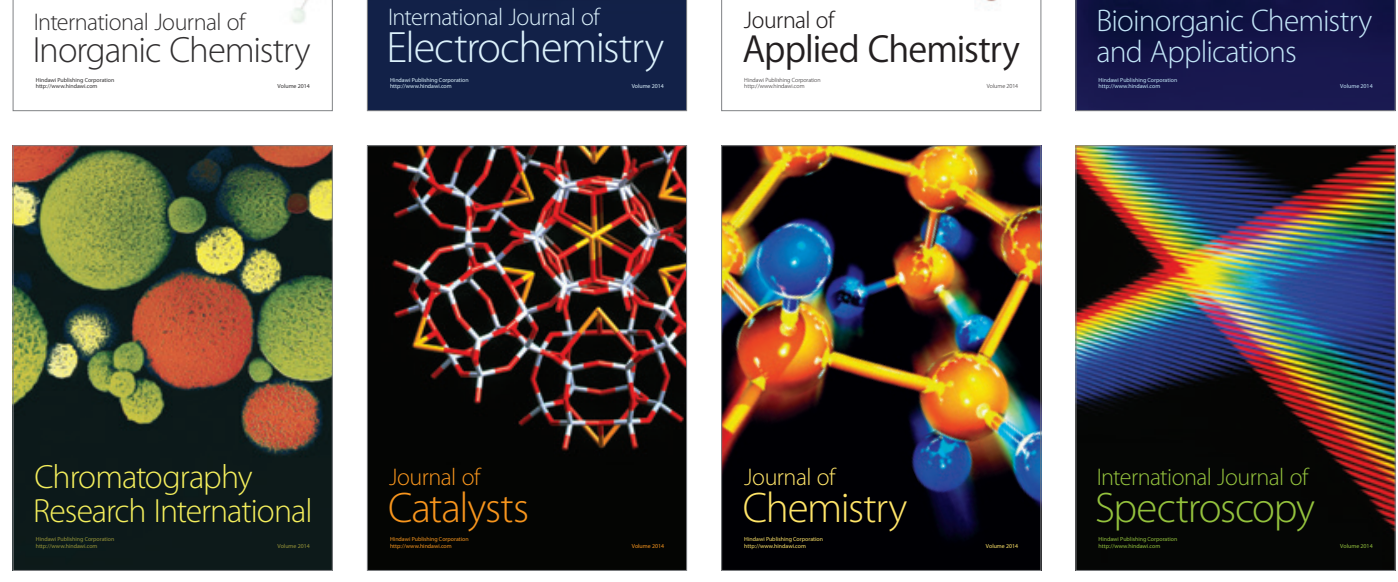